The role of fluid flow and intermetallic phases in the formation of the primary Al-phase in AISi alloys

This article has been downloaded from IOPscience. Please scroll down to see the full text article.

2012 IOP Conf. Ser.: Mater. Sci. Eng. 27012024

(http://iopscience.iop.org/1757-899X/27/1/012024)

View the table of contents for this issue, or go to the journal homepage for more

Download details:

IP Address: 129.247.247.240

The article was downloaded on 12/01/2012 at 14:53

Please note that terms and conditions apply. 


\title{
The role of fluid flow and intermetallic phases in the formation of the primary Al-phase in AlSi alloys
}

\author{
P Mikołajczak $^{1,2}$ and L Ratke ${ }^{1}$ \\ ${ }^{1}$ Institut für Materialphysik im Weltraum, German Aerospace Centre, Linder Höhe, \\ 51170 Cologne, Germany \\ ${ }^{2}$ Institute of Materials Technology, Poznan University of Technology, Piotrowo 3 , \\ 60-965 Poznan, Poland \\ E-mail: Piotr.Mikolajczak@put.poznan.pl,Lorenz.Ratke@dlr.de
}

\begin{abstract}
In secondary AlSi alloys, the presence of small amounts of Fe causes the formation of intermetallic phases, which have a negative effect on mechanical and physical properties of castings. To understand the effect of fluid flow on the microstructure and intermetallic phases, Al-5/7/9 wt pet Si 0.2/0.5/1.0 wt pet Fe alloys have been directionally solidified under defined thermal (gradient $3 \mathrm{~K} / \mathrm{mm}$, solidification velocity $0.04 \mathrm{~mm} / \mathrm{s}$ ) and fluid flow (rotating magnetic field $6 \mathrm{mT}$ ) conditions. The primary $\alpha$-Al phase and intermetallic phases were studied using light microscopy and SEM with EDX. The influence of fluid flow and intermetallic phases ( $\beta$ $\mathrm{Al}_{5} \mathrm{FeSi}$ ) on microstructure was characterized by changes of primary and secondary dendrite arm spacing and specific surface area of the dendrites. We observe a pronounced effect of flow on the length of the intermetallic precipitates, a macro-segregation $\mathrm{Fe}$ and $\mathrm{Si}$ and even small amounts of iron and thus intermetallics reduce possible effects of flow on microstructural parameters.
\end{abstract}

\section{Introduction}

In the automotive, aerospace, and general engineering industry, aluminium-silicon cast alloys are widely used due to their low densities, low cost and acceptable mechanical properties. The mechanical properties of aluminium alloys are however, adversely affected by even small amounts of iron. The solid solubility of iron in aluminum is very low. This leads to the formation of intermetallic compounds, whose nature depends strongly on other impurities, alloying elements and solidification conditions. Beside many other phases [1], the equilibrium phases in low-alloyed Al-Fe-Si material are reported $[2,3,4]$ to be: $\theta-\mathrm{Al}_{3} \mathrm{Fe}$ (monoclinic), $\alpha-\mathrm{Al}_{8} \mathrm{Fe}_{2} \mathrm{Si}$ (hexagonal), and $\beta-\mathrm{Al}_{5} \mathrm{FeSi}$ (monoclinic). The needle Fe-containing phase $\left(\beta-\mathrm{Al}_{5} \mathrm{FeSi}\right)$ is the most harmful one for the mechanical properties of $\mathrm{Al}-\mathrm{Si}$ cast alloys. Steinbach et al [5] measured $\beta-\mathrm{Al}_{5} \mathrm{FeSi}$ needles in $\mathrm{AlSi} 7 \mathrm{Fe} 1$ to have lengths between $100-350 \mu \mathrm{m}$, whereas in [3] sizes of only $5-10 \mu \mathrm{m}$ are reported. The $\beta$ needles have a chemical composition of approximately $61 \mathrm{wt} . \% \mathrm{Al}, 26 \mathrm{wt} . \% \mathrm{Fe}$ and $13 \mathrm{wt} . \% \mathrm{Si}[4,6,7,8]$ and monoclinic crystallographic structure with $\mathrm{a}=0.616 \mathrm{~nm}, \mathrm{~b}=0.6175 \mathrm{~nm}$ and $\mathrm{c}=2.081 \mathrm{~nm}$ [9-12]. These phases cause porosity [13,14], act as stress concentrators [15-17] and promote crack initiation and lower fatigue life. The possibility of modifying $\beta-\mathrm{Al}_{5} \mathrm{FeSi}$ intermetallics into less damaging phases could help industry to reach higher quality level in castings. One of the methods being discussed in the last years is artificial melt flow, generated e.g. by rotating magnetic field (RMF) $[5,18,19]$. The present paper 
studies interactions between fluid flow, intermetallics and primary Al-phase during directional solidification of AlSiFe alloys.

\section{Experimental}

The study encompassed nine aluminum alloys with 5, 7 and 9 wt.\% $\mathrm{Si}$ and $0.2,0.5$ and $1.0 \mathrm{wt} . \% \mathrm{Fe}$ prepared from pure components. The cylindrical specimens were solidified directionally under controlled conditions upwards in ARTEMIS-3 facility [20,21,22] with a temperature gradient of $\mathrm{G}=3$ $\mathrm{K} / \mathrm{mm}$ and a solidification velocity of $\mathrm{v}=0.04 \mathrm{~mm} / \mathrm{s}$, with and without fluid flow activated inside the specimen by a rotating magnetic field (RMF). Three pairs of coils yield magnetic fields up to $6 \mathrm{mT}$ inducing first an azimuthal flow, and additionally secondary flows in radial and axial directions [23]. The flow velocities are around $10 \mathrm{~mm} / \mathrm{s}$. Due to the extremely low thermal conductivity of the aerogel crucible the isotherms in the solidifying specimens are planar and the transparency allows to optically control the solidification velocity.

The solidified samples were cut at a height of $45 \mathrm{~mm}$ (for longitudinal section) and $50 \mathrm{~mm}$ (for cross section) from the bottom heater. The metallographic microsections were prepared with a micromilling machine and polished. The microscopic observations were looked at in an optical microscope (Axio Imager, Carl Zeiss, Germany) and in a SEM (LEO 1530 VP). The composition of phases was investigated with EDX (Oxford INCA System).

On the cross sections microstructure parameters in four specified areas A, B, C, and D (figure 1) at a magnification of 200 were measured. The areas with dimensions $530 \times 710 \mu \mathrm{m}$ were located respectively $450,1300,2600$, and $4000 \mu \mathrm{m}$ from the outer specimens surface (figure 1 ). In the selected areas the length of $\beta$ was measured and their average length calculated $\mathrm{L}_{\beta \text {-avg }}$, which were displayed on charts in function of the distance from outer specimen surface. The measurement of about 14000 intermetallics allowed us to construct histograms of $\beta-\mathrm{Al}_{5} \mathrm{FeSi}$ population. Primary Al-phase was characterised by calculating primary dendrite stem spacing PDS, secondary dendrite arm spacing

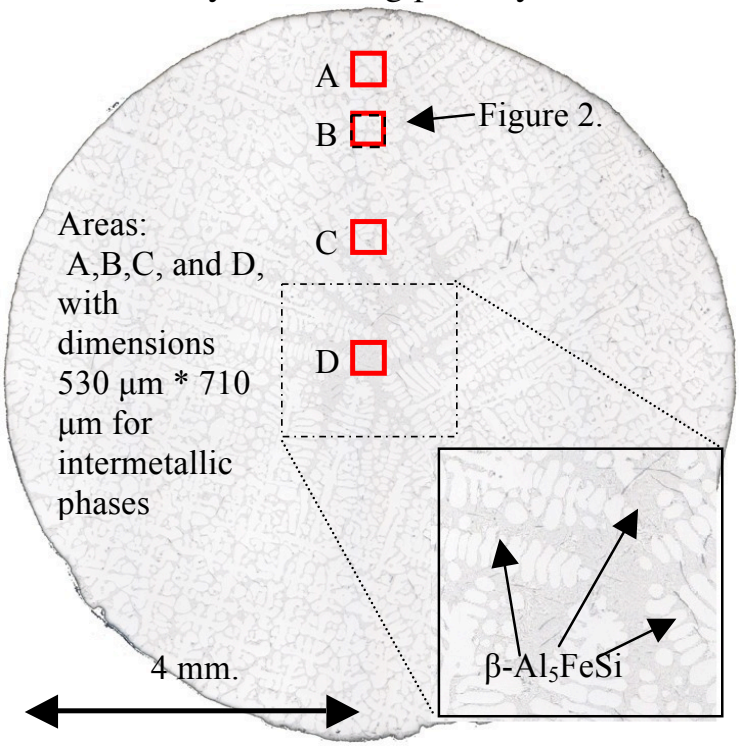

Figure 1. A microstructure on the cross-section of the specimen of Al-5 wt.\% Si-0.5 wt\% Fe solidified under influence of a rotating magnetic field $(\mathrm{G}=3 \mathrm{~K} / \mathrm{mm}, \mathrm{v}=0.035 \mathrm{~mm} / \mathrm{s}, \mathrm{B}=6 \mathrm{mT})$.

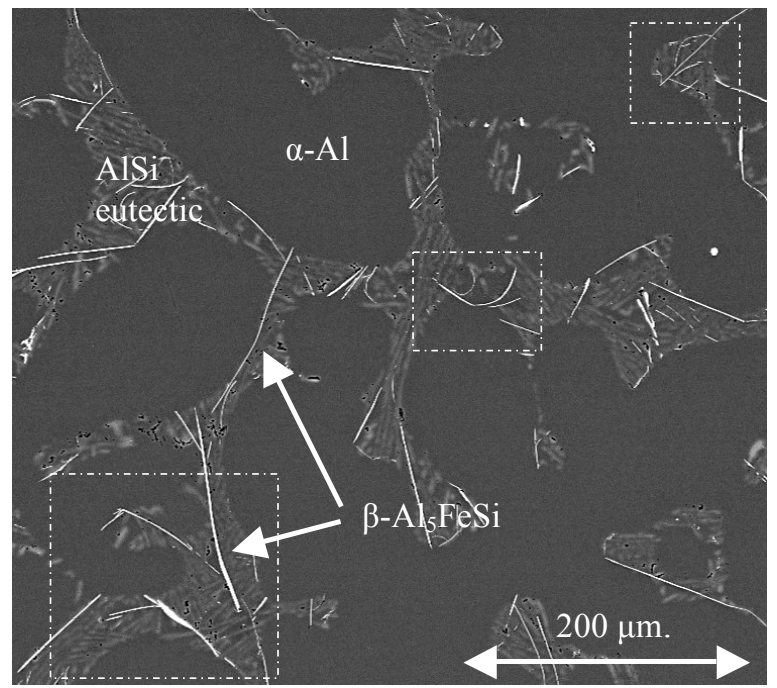

Figure 2. Enlarged micrograph of the specimen shown in figure 1 . The primary $\alpha$-Al phase (dark grey) and $\beta-\mathrm{Al}_{5} \mathrm{FeSi}$ needles (white colour) are pointed.

SDAS and specific surface of the dendrites $S_{v}$ calculated from the measured perimeter and the enclosed area of the $\alpha$-Al-dendrites. 


\section{Results and discussion}

In the microstructure of AlSiFe alloys (figure 1) dendrites, embedded in a eutectic matrix and also iron rich intermetallic phases (white in figure 2) are visible. The most detrimental $\beta-\mathrm{Al}_{5} \mathrm{FeSi}$ needles are located between dendrites and especially in larger eutectic areas [18]. We noticed $\beta$-needles appearing broken (figure 2) with a chemical composition of $67.2 \mathrm{wt} . \% \mathrm{Al}, 17.4 \mathrm{wt} . \% \mathrm{Fe}, 15.4$ wt.\% Si and also curved $\beta$ with 52.2 wt.\% Al, 28.5 wt.\% Fe and 19.2 wt.\% Si.

On all specimens treated by RMF we have observed a solute segregation, and the EDX results confirmed the presence of the eutectic core in the centre (figure 1). The concentration of $\mathrm{Si}$ in the Al-5 wt.\% Si alloy is lower than the average one near the sample periphery $(-20 \%)$, whereas in the center it is larger by $80 \%$. In Al-7 wt.\% Si we have a decrease of Si concentration by $-20 \%$ at the periphery and a centerline increase of $60 \%$. The values for Al-9 wt. $\%$ Si are $-20 \%$ at the periphery and $+40 \%$ in the center. The segregation of $\mathrm{Fe}$ is similar to $\mathrm{Si}$ although in this case the uncertainty of the EDX measurements is larger.

The average length $\mathrm{L}_{\beta}$ of all $\beta-\mathrm{Al}_{5} \mathrm{FeSi}$ needles changes from the sample periphery towards the sample centre in Al-5 wt.\% Si-0.2/0.5/1.0 wt.\% Fe alloys due to fluid flow. In areas A and B stirring causes a decrease of average length and for higher iron containing alloys ( 0.5 and $1.0 \mathrm{wt} \% \mathrm{Fe})$ also in area C. In the center (area D) the opposite situation was found. Application of RMF causes an increase of the average length $\mathrm{L}_{\beta}$. For the specimens solidified without stirring (without RMF, $0 \mathrm{mT}$ ) the value of $\mathrm{L}_{\beta}$ decreases across the sample from the outer specimen surface (near area $\mathrm{A}$ ) to the centre (area $\mathrm{D}$ ), and for the specimens treated with forced convection (RMF, $6 \mathrm{mT}$ ) it seems to be constant. The results for AlSi7 and AlSi9 alloys have presented similar observation.

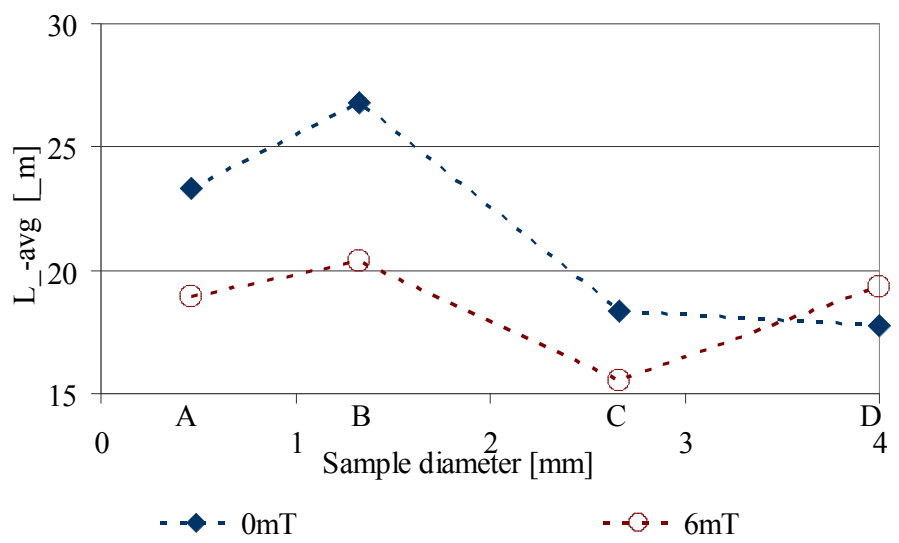

Figure 3. The averaged value $\mathrm{L}_{\beta \text {-avg }}$ from all investigated alloys (Al-5/7/9 wt. \% Si-0.2/0.5/1.0 wt. \% Fe) for the $\mathrm{L}_{\beta}$ of $\beta-\mathrm{Al}_{5} \mathrm{FeSi}$ on the cross section of specimens solidified without $(\mathrm{B}=0 \mathrm{mT})$ and with RMF $(\mathrm{B}=6 \mathrm{mT})$ in areas $\mathrm{A}, \mathrm{B}, \mathrm{C}$, and $\mathrm{D}$ (figure 1 ).

For more general conclusions the results of $\mathrm{L}_{\beta}$ were collected from all studied alloys Al-5/7/9 wt. \% $\mathrm{Si}-0.2 / 0.5 / 1.0 \mathrm{wt} \% \mathrm{Fe}$ in one chart (figure 3 ), showing the averaged value of $\mathrm{L}_{\beta \text {-avg }}$ (in specified areas A, B, C, and D). This averaging over all alloys might seem strange, but since in all samples the trends are very similar, we thought it is helpful to recognize the overall trends. The forced flow with RMF causes very clearly a decreasing of the averaged $\mathrm{L}_{\beta}: 19 \%$ in area $\mathrm{A}, 24 \%$ in area $\mathrm{B}$, and $15 \%$ in area $\mathrm{C}$. Generally, in dendritically structured areas A, B, and C the change amounts to $-20 \%$, and otherwise in area $\mathrm{D}, 9 \%$ growth can be seen. The averaged $\mathrm{L}_{\beta}$ decreases also across the specimen (from the outer specimen surface to the center) for specimens solidified without forced flow $(0 \mathrm{mT})$, and is almost the same for stirring. Simultaneously EDX analysis showed a $20 \%$ and $50 \%$ decrease of Si and Fe content respectively. This action of melt stirring in the outer sample ring suggests, that one cause for the shortening of the $\beta$ phases needles is the lower $\mathrm{Si}$ and Fe concentration there. Since, however the 
length is almost constant across specimens if forced flow is applied there must also be another effect acting. The positive centerline segregation of around $80-100 \%$ would suggest that one observes longer needles in the center. This is not the case (figure 3).

The observed shortening of the $\beta$ needles is consistent with measurements reported by Nafisi [24]. For castings solidified in sand moulds (cooling rate $3.3^{\circ} \mathrm{C} / \mathrm{s}$ ) that measured an average length of $\mathrm{L}_{\beta}=9$ $10 \mu \mathrm{m}$ and with the application of RMF 7-8 $\mu \mathrm{m}$. Casting into a preheated copper mold (cooling rate $\left.4.8{ }^{\circ} \mathrm{C} / \mathrm{s}\right)$ gave $\mathrm{L}_{\beta}=4-5 \mu \mathrm{m}(0 \mathrm{mT})$ and about $4-5 \mu \mathrm{m}$ (very weak increase) with melt stirring. The decrease is $15 \%$ for sand and 5\% for permanent mold casting. Fang et al. [25] observed a shortening of $\beta$ phases from $75 \mu \mathrm{m}$ to $15 \mu \mathrm{m}$ in an LM25 alloy, and for LM24, in which $\beta-\mathrm{Al}_{5} \mathrm{FeSi}$ usually achieves lengths of 95-110 $\mu \mathrm{m}$ these were completely eliminated after application of strong mechanical stirring in the semi-solid state. In the rheo die casting technique used by Fang et al, the alloy was sheared with high shearing rates of $500 \mathrm{~s}^{-1}$ for times $45 \mathrm{~s}$ at $580{ }^{\circ} \mathrm{C}$ and $590{ }^{\circ} \mathrm{C}$.

Figure 4 shows one of the measured histograms of $\beta-\mathrm{Al}_{5} \mathrm{FeSi}$ needles comparing results of solidification without and with RMF for the chosen alloy AlSi5Fe05 and area B (figure 1). On the histogram are presented also: average length $\mathrm{L}_{\beta}(34 \mu \mathrm{m}-0 \mathrm{mT}, 27 \mu \mathrm{m}-6 \mathrm{mT})$, number density $\mathrm{n}_{\beta}$ $\left(383 \mathrm{~mm}^{-2}-0 \mathrm{mT}, 418 \mathrm{~mm}^{-2}-6 \mathrm{mT}\right.$ ) and maximal lengths $\mathrm{L}_{\beta-\max }$ for measured $\beta-\mathrm{Al}_{5} \mathrm{FeSi}$ needles $(118$ $\mu \mathrm{m}-0 \mathrm{mT}, 164 \mu \mathrm{m}-6 \mathrm{mT}$ ). Fluid flow seems to shift the size distribution of $\beta$-needles to smaller values (a higher population of the size classes below $20 \mu \mathrm{m}$. But occasionally also very long needles can be observed with and without fluid flow. Similar results were obtained for the other sample areas and other alloys.

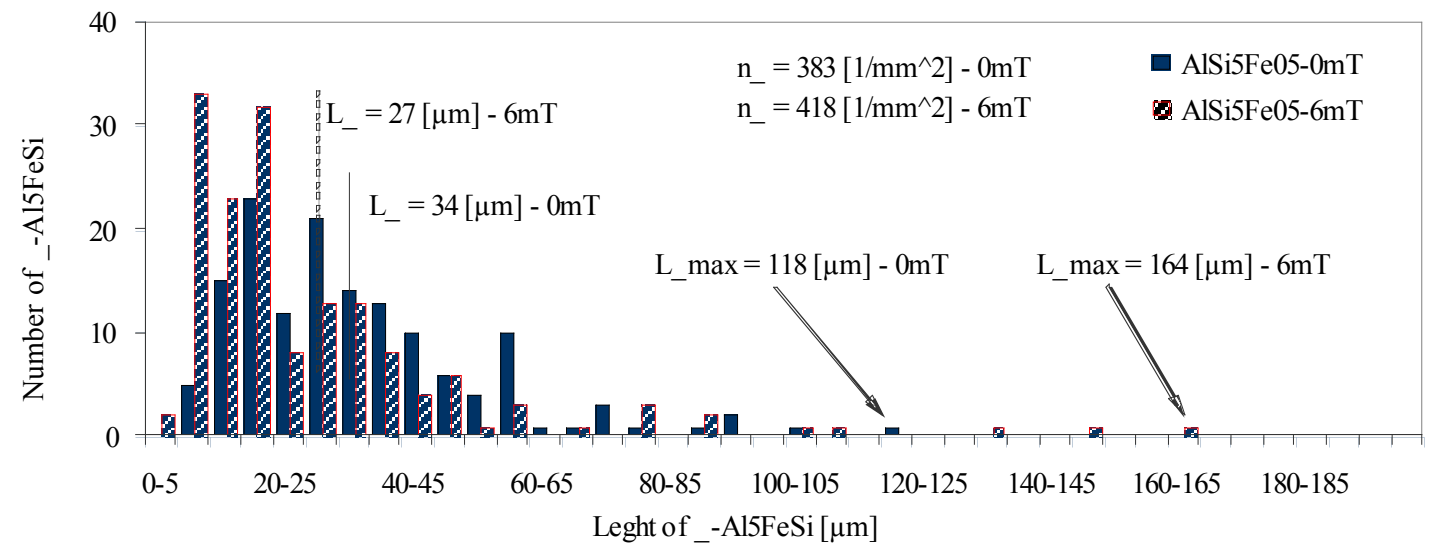

Figure 4. The histogram of the measured $\beta-\mathrm{Al}_{5} \mathrm{FeSi}$ phases in area $\mathrm{B}$ (figure 1) for Al-5 wt. \% Si-0.5 wt. \% Fe; on the cross section of specimens solidified without $(\mathrm{B}=0 \mathrm{mT})$ and with $\mathrm{RMF}(\mathrm{B}=6 \mathrm{mT})$.

The histograms of all samples disclose that forced flow causes a higher number of short needles (5-40 $\mu \mathrm{m}$ ) determining the smaller average length $\mathrm{L}_{\beta}$. Thus the second effect mentioned causing a shortening of the needles by stirring (see above) might be a higher number density caused by higher number of nucleants.

Table 1. Primary Dendrite Spacing PDS $[\mu \mathrm{m}]$

\begin{tabular}{|c|c|c|c|c|c|c|c|c|c|}
\hline & \multicolumn{3}{|c|}{ AlSi5 } & \multicolumn{3}{|c|}{ AlSi7 } & \multicolumn{3}{|c|}{ AlSi9 } \\
\hline & $\mathrm{Fe} 02$ & $\mathrm{Fe} 05$ & $\mathrm{Fe} 10$ & $\mathrm{Fe} 02$ & $\mathrm{Fe} 05$ & $\mathrm{Fe} 10$ & $\mathrm{Fe} 02$ & $\mathrm{Fe} 05$ & Fe10 \\
\hline $0 \mathrm{mT}$ & 532 & 544 & 534 & 590 & 572 & 591 & 708 & 645 & 499 \\
\hline $6 \mathrm{mT}$ & 331 & 374 & 319 & 404 & 408 & 383 & 400 & 441 & 328 \\
\hline
\end{tabular}


Primary dendrite stem spacing (table 1) decreases as expected under forced convection and agrees with results for AlSi7Fe10 [5] and A367 [18] alloys. As mentioned in [18, 29, 30] convection causes an increase of solutal supercooling right between dendrite stems and thus tertiary arms can become new primary stems. We see a PDS increase with increasing Si content, but almost independent of the iron content.

According to [26-28] PDS is proportional to the square root of the freezing range and inversely proportional to the forth root of the solidification velocity and the square root of the temperature gradient. Increase in Si content decreases the freezing range and thus causes a decrease in primary dendrite spacing. We observe the opposite, which points to the fact, that with increasing Si content the amount of fraction eutectic increases, which separates the primary stems from each other. A first order calculation shows that taking the eutectic fraction into account, the primary spacing increases linearly with $\mathrm{Si}$ content. Fluid flow changes reduce the slope in this linear relation.

Looking at the data in table 2, we first notice that the SDAS decreases with increasing Si content as expected from coarsening theory [26, 27]. This is true for the case with and without fluid flow. Comparing the SDAS with and without fluid flow quantitatively, it is apparent, that within the experimental scatter the secondary dendrite arm spacing is only weakly affected by fluid flow at best. This observation is in contrast to results for binary AlSi, AlSiMg (A357) and AlSiCu alloys [18], but similar to results [5] for Al.-7wt.\% Si-1wt.\% Fe pointing to an independence of SDAS on fluid flow (caused by a rotating magnetic field RMF) if intermetallics are present in the interdendritic region.

Table 2. Secondary Dendrite Arm Spacing SDAS $[\mu \mathrm{m}]$

\begin{tabular}{|c|c|c|c|c|c|c|c|c|c|}
\hline & \multicolumn{3}{|c|}{ AlSi5 } & \multicolumn{3}{|c|}{ AlSi7 } & \multicolumn{3}{|c|}{ AlSi9 } \\
\hline & $\mathrm{Fe} 02$ & $\mathrm{Fe} 05$ & $\mathrm{Fe} 10$ & $\mathrm{Fe} 02$ & $\mathrm{Fe} 05$ & $\mathrm{Fe} 10$ & $\mathrm{Fe} 02$ & $\mathrm{Fe} 05$ & Fe10 \\
\hline $0 \mathrm{mT}$ & 133 & 142 & 136 & 110 & 110 & 106 & 81 & 78 & 67 \\
\hline $6 \mathrm{mT}$ & 128 & 127 & 125 & 102 & 105 & 107 & 62 & 58 & 69 \\
\hline
\end{tabular}

The specific surface area (table 3) does not change at all under stirring, but increases with increase of $\mathrm{Si}$ content and weaker with Fe. According to [31] $\mathrm{S}_{\mathrm{v}}$ is inversely proportional to the cube root of solidification time, which is proportional [28] to secondary dendrite arm spacing, and inversely proportional to the coarsening constant $[28,32]$, which among other things is proportional to solute concentration [32], and that makes the increase of $S_{v}$ with $S i$ comparable to earlier studies.

Table 3. Specific surface of the dendrites $\mathrm{S}_{\mathrm{v}}\left[\mu \mathrm{m}^{-1}\right]$

\begin{tabular}{|c|c|c|c|c|c|c|c|c|c|}
\hline & \multicolumn{3}{|c|}{ AlSi5 } & \multicolumn{3}{|c|}{ AlSi7 } & \multicolumn{3}{|c|}{ AlSi9 } \\
\hline & $\mathrm{Fe} 02$ & $\mathrm{Fe} 05$ & Fe10 & $\mathrm{Fe} 02$ & $\mathrm{Fe} 05$ & Fe10 & $\mathrm{Fe} 02$ & $\mathrm{Fe} 05$ & Fe10 \\
\hline $0 \mathrm{mT}$ & 0.0260 & 0.0291 & 0.0307 & 0.0364 & 0.0379 & 0.0403 & 0.0429 & 0.0453 & 0.0474 \\
\hline $6 \mathrm{mT}$ & 0.0278 & 0.0308 & 0.0303 & 0.0386 & 0.0382 & 0.0394 & 0.0399 & 0.0456 & 0.0467 \\
\hline
\end{tabular}

The results presented above can be summarised as:

1. fluid flow reduces the average length of $\beta$ phases in the dendritic outer ring of the specimens and increases it the eutectic centre.

2. The primary dendrite stem spacing is reduced by fluid flow, while

3 . The secondary dendrite arm spacing is unaffected.

The same applies for the specific interface area of the dendritic network. 
As discussed, two competing effects seem to regulate the lengths of intermetallic phases: on the one hand the negative segregation of $\mathrm{Si}$ and $\mathrm{Fe}$ in the outer dendritic ring impedes growth at a constant number of density of growth sites. The positive segregation in the centre on the other hand leads to an increased nucleation rate of the $\beta$ needles (larger supersaturation) and thus the available amount of $\mathrm{Si}$ and $\mathrm{Fe}$ is distributed on a larger number of precipitates leading also to a restricted growth. This gives an almost constant length in the case of fluid flow. The nucleation rate may in addition be affected directly by the flow. The $\beta$ needles form a few millimetres behind the dendrite tips. Fluid flow can wash out parts of the precipitates and transport them into the melt ahead, where they will be partially dissolved depending on their path and time moving with the melt flow. They are then distributed again in the mush network. There they can act as nucleation and growth centres. Depending on the strength of both effects: a decrease or increase in needle length can occur.

The primary dendrite spacing decreases under stirring as expected. But the influence of melt flow is limited because already secondary dendrite arm spacing is very weakly affected and the specific surface area stays constant. This can be understood by reasoning, that the primary spacing is dictated by solutal supercooling effects ranging down into the mush by approximately 30 to 50 dendrite tip radii (a few hundred micrometers). The secondary arm spacing is dictated by coarsening processes along the length of the mush and thus flow must be able to penetrate deeper into the mush. It seems that even small amounts of iron-silicon-aluminides act as filter and damp convection drastically.

\section{Summary and Conclusions}

Directionally solidified AlSiFe alloys were solidified directionally without and with influence of fluid flow. The intermetallic needle like precipitates of $\mathrm{Al}_{5} \mathrm{SiFe}$ are affected by fluid flow itself and act themselves on the microstructure of the primary dendritic network of $\alpha$-Aluminium. Melt flow makes the intermetallics shorter by about $20 \%$ shortening in dendritic regions and longer in eutectic ones. Fluid flow decreases the primary dendrite spacing and only very weakly affects secondary dendrite arm spacing and the specific surface. More detailed studies dealing with other aspects characterising interaction between forced flow, intermetallic and primary Al-phase are currently conducted.

\section{Acknowledgments}

This work was carried out in the framework of a Marie Curie Intra European Fellowship, supported by Seventh Framework Program GA No 235874, PIEF-GA-2009-235874 of the European Union.

\section{References}

[1] Skjerpe P, Metallurgical Transactions A, Volume 18A, February 1987-189

[2] Rilvin V G, Raynor G V, Int. Metall. Rev., 1981, vol. 3, pp. 133-52

[3] Shabestari S G, Mater. Sci. Eng. A 383 (2004) 289-298

[4] Khalifa W, et al., Metall. Mater. Trans. A, Volume 34A, March 2003-807

[5] Steinbach S, Ratke L, Trans. Indian Met., Vol. 60, Nos. 2-3, April-June 2007, pp 137-141

[6] Sergeev L N, Rimmer B I, Metallurgy, 1937, (9/10), 112-126

[7] Pratt J N, Raynor G V, J. Inst. Met., 1951, 79, 211-232

[8] Obinata I, Komatsu N, Nippon Kinyoku Gakkai + Si, 1955, 19, 197-201

[9] Kral M V, Mater. Lett. 59 (2005) 2271 - 2276

[10] Kuijpers N, et al. Mater. Charact. 49 (2003) 409- 420

[11] Kral M V, et al., Scr. Mater. 51 (2004) 215-219

[12] Skjerpe P, Structure of AlmFe. Acta Crystallogr. (1988). B44, 480-486

[13] Dinnis A et al., Mater. Sci. Eng., A 425 (2006) 286-296

[14] Crepeau P N, AFS Trans. 103 (1995) 361

[15] Samuel F H, Samuel A M, Doty H W, AFS Trans. 104 (1996) 893

[16] Fiouzdor V, Mater. Sci. Eng., A 454-455 (2007)

[17] Tash M, et al., Mater. Sci. Eng., A4430 (2007)

[18] Steinbach S, Ratke L, Metall. Mater. Trans. Vol. 38A, July 2007, 1388-1394 
[19] Steinbach S, et al., Materials Science Forum, 2006, Vols. 519-521, pp 1795-1800

[20] Alkemper J, et al., Cryst. Growth, 1998, vol. 191, pp. 252-60

[21] Sous S, Ratke L, Z. Metallkd., 2005, vol. 96 (4), pp. 362-69

[22] Steinbach S, Ph.D. Thesis, RWTH, Aachen, 2005

[23] Hainke M, Ph.D. Thesis, Technical Faculty Erlangen-Nuremberg, Germany, 2004

[24] Nafisi S, et al., Mater. Sci. Eng., A 432 (2006) 71-83

[25] Fang X, et al., Mater. Sci. Eng., A 445-446 (2007) 65-72

[26] Kurz W, Fisher D J, Fundamentals of solidification, Trans. Tech. Public., Switzerland, (1986)

[27] Dantzig J A, Rappaz M, Solidification, EPFL Press, Switzerland 2009

[28] Stefanescu D M, Science and Engineering of Casting Solidification. Springer 2009.

[29] Beckerman C, et al., J. Comp. Phys., 1999, vol. 154, pp. 468-96

[30] Lehman P, et al., J. Cryst. Growth, 1998, vol.183, pp 690-704

[31] Kammer D, Voorhees P, Acta Mater., 2006, 54, 1549-1558

[32] Voorhees P, Glicksman E, Metall.Trans., 1984, 15A, 1081 